\title{
Towards a design for the project-based organization 2 s
}

\author{
Maxim Miterev a,b,*, Mauro Mancini ${ }^{\mathrm{b}}$, Rodney Turner ${ }^{\mathrm{b}, \mathrm{c}}$ \\ ${ }^{a}$ Department of Industrial Economics and Management, KTH Royal Institute of Technology, Lindstedtsvägen 30, SE-100 44 Stockholm, Sweden \\ ${ }^{\mathrm{b}}$ Dipartimento di Ingegneria Gestionale, Politecnico di Milano, via Lambruschini 4/B, 20156 Milan, Italy \\ c SKEMA Business School, Avenue Willy Brandt, 59777 Euralille, Lille, France
}

\begin{abstract}
Organization design is an established field of research within organization studies, focusing on different organizational forms, the array of the design strategies available to managers and their external and internal contingencies. However, our understanding of the complementary design choices available to managers of project-based organizations is limited. Building on both organization theory and design and project management literature this study identifies design choices available for the design of the project-based organization. Adopting the contingency perspective, it reviews the literature on project-based organizations to explore key factors that influence the design of the project-based organization in comparison with more traditional organizations. The resulting model offers a starting point for further studies on the design of the project-based organization. The study concludes by suggesting a research agenda in light of the results.
\end{abstract}

Keywords: Organization design; New forms of organization; Project-based organization; Contingency theory; Design choices; Organizational project management; Management by projects

\section{Introduction}

Although the project-based or project-oriented organization has been recognized in the literature for over 25 years, (Gareis, 1990; Hobday, 2000; Lindkvist, 2004; Whitley, 2006; Cattani et al., 2011), surprisingly there has been no definitive, holistic model developed for its design. Turner and Keegan (1999, $2000,2001)$ and Keegan and Turner $(2000,2001,2002)^{1}$ made

\footnotetext{
is We would like to thank the participants and reviewers of the EURAM Conference 2016, where an earlier version of the paper was presented, and three anonymous IJPM reviewers for their helpful and constructive comments. We are also grateful to Associate Editor Dr. Martina Huemann for handling the manuscript.

* Corresponding author at: Lindstedtsvägen 30, INDEK, KTH, 10044 Stockholm, Sweden.

E-mail addresses: maxim.miterev@indek.kth.se (M. Miterev), mauro.mancini@polimi.it (M. Mancini),rodneyturner@europrojex.co.uk (R. Turner)

${ }^{1}$ In the remainder of the paper we refer to these six of these papers as Turner \& Keegan (loc cit)
}

some contribution, but while their original intent was to develop an holistic design for the project-based organization, in the end they described how project-based organizations implement six elements of organization design.

Some of the early attempts at adopting projectbased organization were not successful. Turner \& Keegan (loc cit) identified that was because some organizations changed completely from functional, hierarchical, line management (which they called classical management), to a totally project-focused approach. In doing away with the functional hierarchy, such organizations had lost the strengths the functional hierarchy gives to the organization, and not thought how to replace them with project-based working. We list the strengths they identified in Table 1. (We later adopt Galbraith's (2014) Star Model TM for the design of the projectbased organization, Fig. 1.InTable 1 we show how the five elements of the Star Model correspond to Turner \& Keegan's six strengths of the functional hierarchy.) They also suggested that the functional hierarchy provides the organization with cohesion and culture. They found that organizations that 
Table 1

Six elements of organization design of the project-based organization investigated by Turner and Keegan.

\begin{tabular}{lll}
\hline $\begin{array}{l}\text { Strength the functional } \\
\text { hierarchy gives an } \\
\text { organization }\end{array}$ & $\begin{array}{l}\text { Paper by Keegan \& Turner } \\
\text { showing how that strength } \\
\text { is retained by the project- } \\
\text { based organizations }\end{array}$ & $\begin{array}{l}\text { Corresponding } \\
\text { element of the Star } \\
\text { Model, Fig. 1 }\end{array}$ \\
\hline $\begin{array}{l}\text { Governance } \\
\text { Operational control } \\
\text { Communication }\end{array}$ & $\begin{array}{l}\text { Turner and Keegan }(1999,2001) \\
\text { Turner and Keegan (2000) }\end{array}$ & $\begin{array}{l}\text { Strategy } \\
\text { Process } \\
\text { Careers }\end{array}$ \\
$\begin{array}{l}\text { Individual learning } \\
\text { Organizational learning } \\
\text { and innovation }\end{array}$ & $\begin{array}{l}\text { Keegan and Turner (2000) } \\
\text { Keegan and Turner (2001) }\end{array}$ & $\begin{array}{l}\text { Human resource } \\
\text { Turner et al. (2002) }\end{array}$ \\
\hline
\end{tabular}

adopt pure project-based ways of working lose these strengths, and so need to find alternative structures to replace them. Their conclusion was that it is best for the organization to retain the functional hierarchy and find ways for the functional hierarchy and project structures to work together. They did not offer an holistic solution for the design of the project-based organization, but suggested how it can retain the strengths of the functional hierarchy in the papers cited in Table 1.

It is now recognized that society is substantially projectified (Lundin et al., 2015). Around 40\% of the global economy is project based, using project management as the primary process for producing products and services (Turner et al., 2010). Lundin et al. (2015) have tracked the expansion of projectification. They say it started in the 1930s, with a significant increase in the level of its adoption in the 1960s and again in the 1990s. Now project-based organizations exist in all industries. Not only is this organizational form widespread, but also it is associated with a number of distinct characteristics and contingencies (Söderlund and Tell, 2011), and so the organization design of the project-based organization is of significant interest.

Our aim in this research project is to develop a holistic model for the design of the project-based organization. In this paper we develop an initial research model as a basis for further empirical work. We propose the project-based organization as a new form of organization (Puranam et al., 2014). Further, there has been a re-emergence of interest in the contingency theory of organization design, suggesting that the performance of an

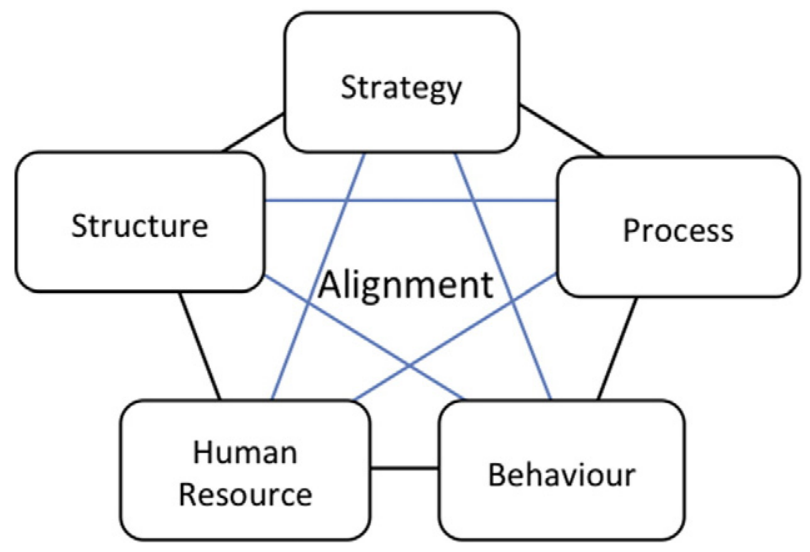

Fig. 1. Modified star model (after Galbraith, 2014). organizational unit is a result of the alignment between its external context and internal arrangements (Van de Ven et al., 2013). We show that with the project-based organization there must also be a fit to the need or choice to adopt project-based ways of working; internal arrangements must reflect the strategic decision to be project-oriented and the resulting churn. There must also be a fit between the project-based ways of working adopted, and the functional hierarchy that Turner \& Keegan (loc cit) suggest must be retained. Our research questions for this initial study are:

RQ1: What design choices are available for the design of the project-based organization?

RQ2: What factors influence the selection of design choices?

The rest of the paper is structured as follows. We review the literature on organization design to choose a design model as the basis for our work. We identify and discuss concepts and perspectives that are useful for developing a model, in particular, contingency, configuration and complementarity, holistic models of organization design and conceptualization of the firm as a web of temporary organizations. We adopt a modified version of Galbraith's (2014) Star Model. We then discuss distinct characteristics of the project-based context and argue for a contingency approach to the design of the project-based organization. We review what has been written in the project management literature since 2008 about the management of the project-based organization, and relate the topics in the papers to our modified version of the Star Model. We find that many people have written about individual elements of the Star Model, but very few people have written about their interdependency and the holistic design of the project-based organization. Finally, we review a small number of papers that have made some contribution to the design of the project-based organization, and add a second star to our model to reflect the contingent requirements that influence the design of the project-based organization. But first we define the project-based organization.

\section{Definitions}

Scholarly interest in organizational implications of organizing by projects has originated from the research on matrix forms of organizations (Galbraith, 1971, 1973, 2008; Knight, 1976; Mintzberg, 1979). The focus in this literature has mainly been on the duality of coordination of project activities through functional and project arrangements and its positive and negative implications (Arvidsson, 2009; Bernasco et al., 1999; Dunn, 2001; Kuprenas, 2003). By identifying the tensions and discussing various archetypes of matrix organizations (Larson and Gobeli, 1989) the literature has provided important foundation for the discussion of project-based organizing.

The literature has several names for the project-based organization (Sydow et al., 2004), including project-based organization (Turner \& Keegan, loc cit), project-based firm (Lindkvist, 2004; Prencipe and Tell, 2001), multi-project firm (Geraldi, 2008, 2009), project-intensive firm (Söderlund and Bredin, 
2006), multi-project organization (Canonico and Söderlund, 2010), project-based company (Jerbrant, 2013; Lundin et al., 2015), projectified matrix organization (Arvidsson, 2009), project-oriented organization (Huemann, 2014,2015 ) and the project-oriented company (Gareis, 1990, 2005; Gareis and Huemann, 2007; Huemann et al., $2007^{2}$ ). In order to avoid a confusion, we differentiate between PBOs as permanent structures incorporating multiple projects and project-based enterprises or firms as temporary legal entities created around a specific project outcome (DeFillippi and Arthur, 1998; Whitley, 2006). The focus in this paper is on the former.

Hobday $(1998,2000)$ introduced the concept of the projectled or project-supported organization as one in which the main business processes adopted are routine, but project-based working makes a significant contribution to operations. Turner \& Keegan (loc cit) called the project-based parts of such businesses Type 2 organizations, (see below).

Turner \& Keegan (loc cit) defined the project-based organization as one in which the majority of products or services delivered are against bespoke designs for customers. Their idea was that if the company was delivering bespoke products or services it necessarily needed to use projects to deliver them. Lindkvist (2004) was more to the point; he defines a project-based firm as one which conducts most of its work as projects. Canonico and Söderlund (2010) similarly view the multi-project organization as an organizational unit that rely on many projects executed at the same time. These are bottom up definitions. Most of the work the company does is as projects, because the nature of the products or services delivered requires it. Turner et al. (2012) differentiated between bespoke and tailored products and services. They defined bespoke ones as being against a one off design for the customer; whereas tailored ones are an adaptation of an existing or standard design. Both require a non-routine production process to deliver them, that is project management. Turner \& Keegan also suggest that the project-based organization may be a whole company, or just a business unit within a company. Following Archibald (1992), they defined Type 1 and Type 2 organizations. Type 1 organizations supply customers outside the parent organization, whereas Type 2 organizations supply another business unit within the same parent organization. This was significant in their work because they found that in both situations the governance structure was aligned with the project, which is also the transaction. In routine supply, for Type 1 organizations the governance structure is aligned with the transaction, the contract, whereas in Type 2 organizations it is aligned with the functional hierarchy. Williamson $(1976,1996)$ calls these markets and hierarchies respectively. This demonstrates that the project-based organization requires different organization design to the routine organization.

Gareis \& Huemann (loc cit) define the project-oriented organization as one which:

- defines management by projects as its organizational strategy

\footnotetext{
${ }^{2}$ In the remainder of this paper we refer to these four publications as Gareis \& Huemann (loc cit).
}

- manages its work through projects and programs as temporary organizations

- manages a portfolio of different types of projects and programs, both internal and external

- uses project, program and portfolio management as specific business processes

- has specific permanent organizations such as a portfolio group or project management office to provide integrative functions

- applies a management paradigm which reflects the ability to deal with uncertainty, contradiction, change and collaboration - views itself as being project oriented

This is very much a top down definition; the organization makes the strategic decision to adopt project-based working and views itself as project oriented and has formalized processes and structures in place to support that choice. However, as with Turner \& Keegan above, the organization adopts project-based ways of working. Also, as with Turner \& Keegan, Gareis \& Huemann recognize the need to provide integrative functions, and suggest the use of project-oriented but still permanent constructs such as the project portfolio group and the project management office to do that.

Throughout this paper we will refer to the project-based organization. We use the term project-based organization, rather than firm or company, because project-based organizations can exist in the public and voluntary sector, as well as the private sector. Besides, a project-based organization can represent a separate organizational unit within a larger organization. We also primarily use project-based rather than project-oriented, because that is more common. However, we do differentiate between project-based as indicating the nature of the business processes the organization adopts, and project-oriented as the way the organization views itself. Based on the above, we define the project based organization as one which makes the strategic decision to adopt project, program and project portfolio management as business processes to manage its work, and which views itself as being project-oriented. For projects, programs and portfolios we use the definitions of Turner and Müller (2003) and Turner (2014). Projects and programs are both temporary organizations to which resources are assigned to do work to deliver beneficial change. A program is a collection of projects managed together to deliver strategic change objectives that cannot be achieved by one project on its own. A project portfolio is a permanent organization, consisting of a collection of projects or programs sharing common resources.

\section{Organization design}

There has been resurgence in interest in organization design after certain hiatus (Gulati et al., 2012; Luo and Donaldson, 2013; Van de Ven et al., 2013; Puranam et al., 2014). The research field has evolved considerably since its emergence around 1960s and now spans various levels of organization and encompasses a multitude of theoretical perspectives (Baum and Rowley, 2002). While the early models were relatively simple and focused on few organizational and environmental 
variables, further contributions took a more holistic and sophisticated view on organizations in order to accommodate the complexity of the empirical phenomenon (Van de Ven et al., 2013). This section reviews relevant ideas and concepts from the organization theory and design field that are later used as a theoretical foundation for the design of the project-based organization.

Van de Ven et al. (2013) suggest that the world of organizations is changing, and so must our approaches to theory and research. While the mainstream trend within organizational design literature focuses on inter-organizational and community contexts (Gulati et al., 2012), intraorganizational design choices need to be better understood in a view of internal changes in contemporary organizations. Turner \& Keegan (loc cit) observe a change from classical management to an environment in which business is more unpredictable and rapidly changing. One of the ways organizations change in response to the new conditions is the widespread use of temporary organizational forms, such as projects and programs, (Gareis \& Huemann, loc cit). Lundin et al.(2015) note that the number of new product development projects in a typical company in the car industry has gone from one every two years in the 1940s, to eight a year now. The management of innovation in the car industry now requires a project-led or project-supported organization. Surprisingly, the organization design perspective has not been applied to the project-based context.

Puranam et al. (2014) explain why an organizational form may require a novel design. They say it is for the solution to the four problems of organizing: task division; task allocation; reward provision; and information provision. They define each as a form of mapping: from goals to tasks (task division); from tasks to agents (task allocation); from rewards to agents (reward provision); and from information to agents (information provision). Projectbased organizations use the management of temporary organizations in the form of projects and programs as their primary business processes. Every time a project or program starts or finishes there is a redefinition of task allocation, task division, reward provision and information provision within the organization. So the projectbased organization is a new form of organizations that has a constant churn in the four elements of organization design (Huemann et al., 2007).

\subsection{Contingency theory}

Contingency theory represents an important pillar of organization design (Donaldson, 2001; Van de Ven et al., 2013). The key idea is that activities should be organized differently depending on certain exogenous contingency factors. The scientific dispute in the field revolves around which parameters are the most appropriate as contingency dimensions to classify organizations and what organizational types are used (or should be used) for each of the type. Whereas some of the scholars emphasize environmental dimensions, such as the rate of technological and market change, as the most important contingency factors (Burns and Stalker, 1961; Lawrence and Lorsch, 1967; Thompson, 1967), others focus on technology utilized (Woodward, 1965; Perrow, 1986).
While the contingency theory has been extensively applied at the project level (Hanisch and Wald, 2011), program level (Miterev et al., 2016) and portfolio level (Martinsuo, 2013), its detailed elaboration at the project-based organization level is yet to come. Based on the work of Lengnick-Hall and Lengnick-Hall (1988) and Wright and McMahan (1992), Huemann et al. (2007) and Keegan et al. (2012) suggest that the design of the project-based organization should be aligned in four directions. There should be a fit of the management processes adopted:

- with the strategic decision to be project- oriented

- in the line and on projects

- between different functions

- with the context

\subsection{Holistic models of organization design}

The early contributions were criticized since they relied on few contingency variables and organizational design choices, thereby not reflecting the complexity of organizations. The organization design field has responded with a number of holistic models, aiming to assist the strategists in organization design choices (for example Mintzberg, 1979; Nadler and Tushman, 1999; Galbraith, 2014). An organization design can be based on one of several seminal models (Van de Ven et al., 2013), including:

- The McKinsey 7-S Framework, (Waterman and Peters, 2015)

- Nadler \& Tushman's congruence model, (1999)

- Hackman \& Oldham's job diagnostic survey, (1975)

- Galbraith's information processing or Star Model, (2014)

These models share common features: they all build on contingency perspective; call attention to the coherence among the organization design dimensions; and include similar individual components, for example related to people, structures and processes. Galbraith's Star Model comprises strategy, structure, processes, rewards, and people. The key message of these and similar models is that the organization design scholars and practitioners should consider a broad range of organizational dimensions and to pay attention to their internal coherence and external fit.

Even though such models were shown to be too simplistic to reflect the complexity of modern organizations (Meyer et al., 1993; Doty et al., 1993), they can be useful as analytical frameworks to identify relevant design choices for a new organizational form. In particular, while a lot of modern organization theory is well developed, has moved beyond holistic models and is looking at narrow specific issues, the project-based organization design is a new area, and thus can benefit from applying even basic concepts of the organization theory and design, (walk before you can run). Therefore, using the seminal holistic models can provide the first insights into the design of the project-based organization. 
This study builds upon Galbraith's (2014) model to develop its propositions. The Star Model, Fig. 1, consists of five elements at the nodes of a pentagon, with the word "alignment" at the centre of the star, emphasizing that the five elements must be consistent with each other and with organizational strategy. Galbraith has varied the definition of the five nodes. To incorporate elements of Waterman and Peters' (2015) and Nadler and Tushman's (1999) models, we have chosen the five nodes as starting top and going clockwise: strategy; process; behaviour; human resource; and structure. We have chosen Galbraith's Star Model for this work, because projects can be viewed as systems for processing information (Turner et al., 2010; Winch, 2004). We have already shown, (Table 1) that the five nodes of the star relate to the six strengths of the classically managed organization which Turner \& Keegan (loc cit) suggested that the project-based organization needs to retain. We will also show later that the five nodes can be used to categorize much of the recent research into project-based organizing.

\subsection{Configuration and complementarities perspectives}

The configuration perspective further emphasizes the limitations of the reductionist stance on organization design dimensions and the importance of considering broad arrays of organization design choices at different organizational levels and their interactions. While potentially there are an infinite number of organizational configurations, only some of them are stable and thus can be meaningfully studied (Meyer et al., 1993). Hence, the focus is on the configuration as a whole. Van de Ven et al. (2013), building on March and Simon (1958) and Thompson (1967), identify three types of configuration:

1. systemized program for non-varying repetitive tasks

2. discretionary program of varying, periodically unique tasks

3. development program for novel tasks

A project-based organization undertaking tailored works (as defined by Turner et al., 2012) is performing a discretionary program, and one undertaking bespoke works is performing a development program.

Complementarity perspective offers a few additional twists to the configuration approach. First, it is taking into account performance effects of separate arrangements within the configurations rather than being focused only on the comparison of various configurations as a whole. Second, it distinguishes among different design choices based on their interdependency with others. In the words of Milgrom and Roberts (1995), complementarities are present when "doing more of one thing increases the returns to doing more of another". Finally, it draws attention to the organizational change and particularly to the interplay between changes in organizational configurations and

\footnotetext{
${ }^{3}$ Galbraith uses the word "fit" instead of "alignment". We decided to use a different term to avoid possible confusion with the term "fit" as defined by Maylor et al. (2015) that we build on later in the paper.
}

performance. System wide changes provide better returns, while piecemeal changes can even result in negative dynamics of the organizational performance (Whittington et al., 1999). In line with the contingency perspective, intra-organizational design dimensions should be considered together with salient contextual variables, since particular complementarities differ in various organizational contexts (Ennen and Richter, 2010).

The perspectives of configuration and complementarities are particularly relevant in the context of the project-based organization. As we shall see later, each project as well as each collection of projects (program or portfolio) entail their own set of organization design choices. Therefore, the organization design of the project-based organization is not limited to the design choices at the level of project-based organization and can benefit from applying the configuration and complementarities perspective.

\section{4. 'Molecular units' within organizations}

The perspectives that were discussed so far tend to focus on the organization as a whole as the unit of analysis. As a result, they pay little attention to the different and even conflicting goals, design choices and contingencies that can characterize various parts of the organization. Indeed, large firms are becoming increasingly disaggregated into 'molecular' organizational units (Zenger and Hesterly, 1997). This disaggregation is a result of the stronger performance incentives in the smaller units as well as the improved opportunity for the corporate management to intervene selectively along vertical hierarchy due to information technology development. It also reflects the nature of value creation processes in knowledge economy (Hedlund, 1994). Along the same lines, Lindkvist (2004) discusses the infusion of market-like governance mechanisms within hierarchies in the context of the project-based organization. Therefore, organizations should be viewed as complex networks of governance arrangements, rather than described within simplistic taxonomies viewing the organization as a homogeneous whole (Zenger and Hesterly, 1997).

In the long term, temporal decentralization and subsequent centralization can achieve better performance, particularly in relation to the search for solution to non-decomposable or nearly-decomposable problems (Siggelkow and Levinthal, 2003). This stream of organization science literature is highly relevant for the case of the project-based organization, where projects as temporary organizations (Packendorff, 1995; Lundin and Söderholm, 1995) represent decentralized entities nested in the parent organization (Bergman et al., 2013), whose results are eventually integrated by the more stable (semipermanent or permanent) organizational structures like programs and portfolios, Fig. 2.

\section{Design of the project-based organization}

We now discuss how the above concepts apply to the project-based organization. 


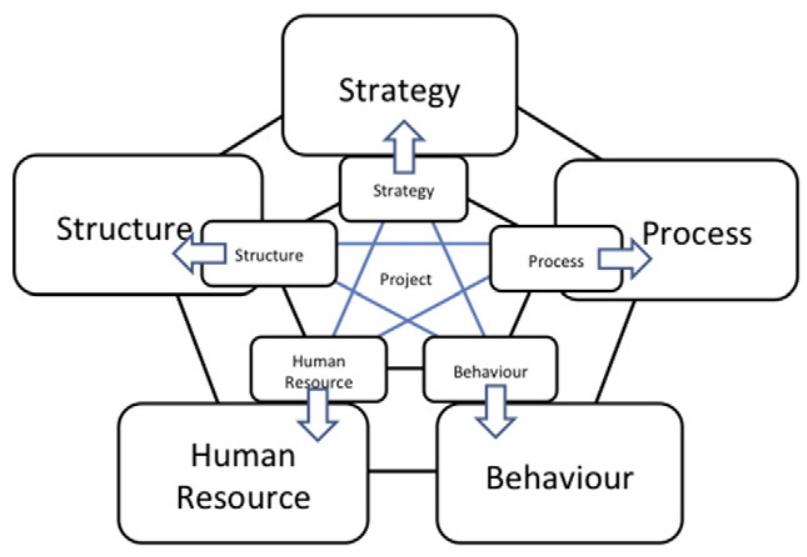

Fig. 2. Projects as temporary organizations nested in the project-based organization.

\subsection{A new form of organization}

Following Puranam et al. (2014) the project-based organization is a new form of organization, and following Gareis \& Huemann (loc cit) we define the project-based organization as one which uses the management of temporary organizations in the form of projects and programs as their primary business processes. As we suggested above, every time a project or program starts, a new agent is created, and every time one finishes an agent ceases to exist. Thus there is a constant churn in the definition of the agents within the organization, and so of the subsequent mapping of task division, task allocation and information provision. Also the people and other resources of the organization, who are themselves agents, are constantly being assigned and reassigned to projects and the functional hierarchy, and so there is changing composition of some agents: projects, programs and functional hierarchy, and other agents, the people and other resources, are constantly being repositioned. This makes the project-based organization different from most forms of organization.

Keegan et al. (2012) discuss the issue of rewards. They say rewards should primarily be assigned via the line organization (functional hierarchy). Temporary, more focused rewards may be assigned via projects, but long-term rewards will be assigned via the line, because they need to be aligned with the long-term goals of the organization. Thus tasks are done on projects and programs, but rewards assigned via the line, and so there is a separation of tasks and rewards not seen in conventional organizations. However, rewards should be based on task performance, and so there needs to be a transfer of information from the task (project) to the agent (line or hierarchy) for the rewards to be appropriately determined.

We have called the five nodes of the Star Model: strategy; structure; process; behaviour and human resource. Chandler (2013) suggests that structure follows strategy, and Skinner $(1969,1974)$ suggests that process also follows strategy. We have represented that in the position of the five nodes of the star. It is more normal in the literature to distinguish organizational behaviour and human resource management
(Turner et al., 2010), and so we have adopted that approach. Behaviour is related to process. Müller (2009) offers behaviour as one of two control mechanisms in organizations (the other being goals), and says that control by behaviours is ensuring adherence to process. In the same vein, Simons (1995) emphasizes the importance of behaviour-oriented levers of control in organizations.

There is support for this model in the literature. Turner $\&$ Keegan (loc cit) dealt with the five elements of the model, as shown in Table 1. Gareis (1990) identified three elements for the management of the project-oriented organization: strategy; structure and culture (related to behaviour). But he also discussed the establishment of related processes. Bergman et al. (2013) track the trajectory by which a company becomes projectized. They suggest a four element model which they track, the four elements being: structure; process; people; and products/offerings. The fourth element products/offerings is linked in the paper to the value that the organization is aiming to provide to its external stakeholders, and hence is related to its strategy. Thus we see in the project management literature there is significant support for the proposition that the five significant elements in the design of the project-based organization are strategy, structure, process, behaviour and people (or human resource).

Finally, we build on Bergman et al. (2013) who view 'firm-based' projects in the project-based organization as temporary organizations nested in, and coupled to their parent organization, Fig. 2. The design choices for these temporary organizations should be aligned with the design choices of the project-based organization as a whole. This conceptualization can be related to two of the themes in the organization design literature discussed in the previous section, namely the disagreggation of large organizations into 'molecular organizational units' (i.e. projects in case of the PBO) and the importance of the complementarity among various design dimensions across multiple organizational levels.

Thus in answer to Research Question 1, we suggest Proposition 1:

Proposition 1.1. The project-based organization requires a novel form of organization design, to address the fact that the definition of the agents of the organization and their assignment is constantly changing.

Proposition 1.2. The design of the project-based organization should be based upon the alignment between strategy, structure, process, organizational behaviour and human resource management.

Proposition 1.3. The corresponding elements on projects within the organization should be aligned with the five elements. Projects within the organization should be aligned with each other, with ongoing routine operations, and with the context.

\subsection{The star model in the project management literature}

To further validate the model, we conducted a review of the project management literature since 2008 , to identify papers on 
the design of the project-based organization. We surveyed the three major journals in the project management field as suggested by Turner et al. (2011). We also surveyed the International Journal of Managing Projects in Business which was too new to cover the 20 years they analysed. Thus, our final sample includes four journals:

- The International Journal of Project Management, (IJPM)

- The Project Management Journal, (PMJ)

- The project management division of the IEEE Transactions in Engineering Management, (IEEE TEM)

- The International Journal of Managing Projects in Business (IJMPiB)

We chose to survey papers since 2008 because Artto and Kujala (2008) conducted a review of the current state of project management research in that year, and identified a number of research themes within the research area that was labelled "Management of the project-based firm". They identified research in four of the five nodes of Fig. 1: strategy; process; structure; and human resource. They did not cover behaviour, including leadership and team working. The only element of behaviour they did consider was stakeholder management under the management of a project network - many firms-one project.

We identified all the papers published in the four journals between January 2008 and December 2015 on the topic of the management of the project-based organization. We identified 177 papers and categorized them according to which of the five elements in Fig. 1 they covered as shown in Table 2. Process and structure are written about considerably more than the other three topics. Table 2 also shows the key themes within each topic.

Presenting the results of the full bibliographic study is outside the scope of this paper, (see Miterev et al., submitted for publication). However, we found that all dimensions of the Star Model have been discussed in the PM literature. Thus the framework used for this study is supported by the project management literature. We also found that none of the papers was dealing with the holistic design of the project-based organization, but some of the papers dealt with how elements of the Star Model interact.

We now look at what factors influence the choice of design options for the project-based organization.

Table 2

Elements of the Star Model covered by the papers in the four journals during the period surveyed.

\begin{tabular}{lll}
\hline Element the Star Model & Number of papers & Key themes \\
\hline Strategy & 44 & $\begin{array}{l}\text { Alignment } \\
\text { Governance } \\
\text { Portfolio and programs } \\
\text { Project office } \\
\text { Structure }\end{array}$ \\
Capability \\
Process & 133 & $\begin{array}{l}\text { Management practices } \\
\text { Culture } \\
\text { Competence } \\
\text { Behaviour }\end{array}$ \\
Human resource & 38 & HRM practices \\
\hline
\end{tabular}

\section{Factors influencing the design of the project-based organization}

Van de Ven et al. (2013) propose that contingency theory is the dominant theoretical construct in the design of organizations. To answer our second research question, we propose a second star model, Fig. 3, to represent the factors influencing the design of the project-based organization. We have placed the five elements of the second star to mirror the elements of Galbraith's star to which they are most related:

- the decision to be project-oriented is a strategic decision that influences the overall strategy of the organization

- that decision says that the project-based working are the main business process that will be adopted by the organization

- it also requires that the organization structure should create a fit between the processes adopted and the decision to be project oriented, between processes in the line and on projects, between processes in different functions, and between the processes adopted and the context

- the organization must adopt a project culture so that behaviours in the organization reflect project-based working

- the churn that project-based working implies requires organizations to adopt human resource management approaches that reflect that churn

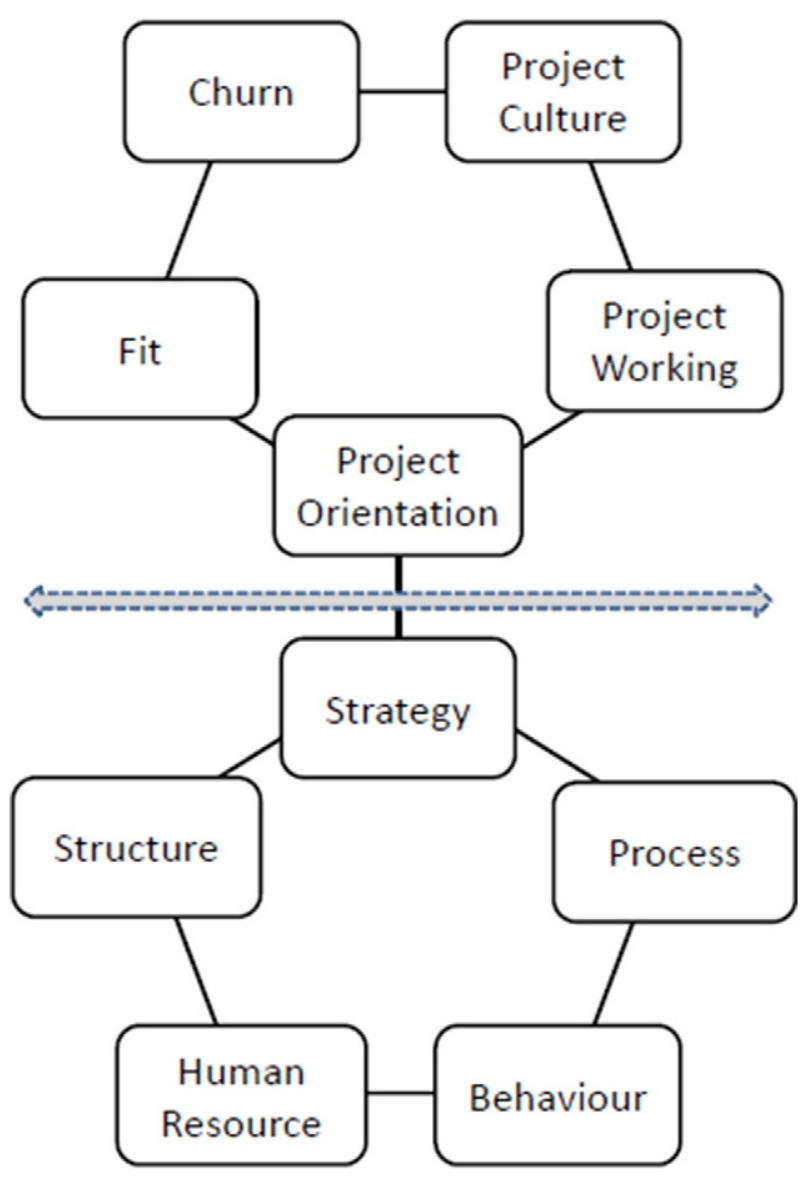

Fig. 3. Factors influencing the design of the project-based organization. 
The five elements in the second star influence each other, and the five factors in Galbraith's star both directly and through the element they are mirrored with.

\subsection{Strategic decision to be project-based}

Gareis \& Huemann (loc cit) say that what they call the project-oriented organization makes the strategic decision to be project-oriented, and views itself as such. Turner \& Keegan (loc cit) suggested that the project-based organization is such perforce. However, they showed that in many organizations delivering tailored or bespoke products or services to clients, the functional hierarchy remains dominant. They suggested that the governance structure should be aligned with the transaction, the project, for both internal and external supply. This is different from routine supply where for internal transactions the governance structure is aligned with the functional hierarchy,(Williamson, 1976, 1996). Functional managers, who are used to being the primary internal mechanism of governance, resist this change. Therefore to be project-oriented, that is to recognize that your business processes are project-based, is a strategic decision, to which everybody in the organization must adhere.

Maylor et al. (2015) also take a strategic approach, by comparison to manufacturing organizations. They review the literature on operations strategy for manufacturing organizations, and consider what it means for project-based organizations. They suggest that the project-based organization has to decide it is project-oriented, and develop an appropriate operational strategy. Several recent studies describe the transition of a company to being project-oriented (Söderlund and Tell, 2009; Bergman et al., 2013; Kwak et al., 2015). Söderlund and Tell (2009) describe the evolution of Asea/ABB over 50 years, through four epochs. They mainly focus on competence development, and through the four epochs, Asea/ABB recognized the need to adopt projectbased ways of working, and designed appropriate structures. The company did not become fully projectoriented until epoch 4. Bergman et al. (2013) trace the development of a telecommuni-cations company through seven stages. Project management became institutionalized in stages 3 and 4, but it was in stage 5 the organization became project-oriented, with projects given representation in the line hierarchy, and project management offices established. Kwak et al. (2015) look at the development of competence by doing a longitudinal study of 30 years in a consulting company in the construction sector in the Middle East. The paper discusses organizational attempts to gradually develop project and program competence and maturity in the organization and introduces a three-stage model of the transition. Project management became institutionalized at the end of the 15 year long stage 1 with the establishment of separate project man-agement divisions within each department. The stage 2 was focused on improving individual competences and performance of the project and program managers. The final stage 3 introduced standardization through a companywide maturity model. None of the organizations took the strategic decision to become project oriented, but all recognized early on (at epoch 1, stage 2, and stage 1 respectively) that projects were a significant part of their business and they needed to adopt project-based ways of working, and all of them recognized, at epoch 4, stage 5 and stage 3 respectively that they were project oriented.

\subsection{Using the management of temporary organizations as business processes}

In the project-based organization, project, program and portfolio management are the business processes adopted for delivering products and services to customers, (Gareis \& Huemann, loc cit; Turner \& Keegan, loc cit). We defined above a project or program as a temporary organization to which resources are assigned to do work to deliver beneficial change. Thus, in terms of the model of Puranam et al. (2014), projects and programs are agents, to which other agents, resources, are assigned, to perform the tasks of the organization. Projects and programs are agents; project and program management are the processes, or tasks, adopted. Gareis \& Huemann (loc cit) propose that the project-oriented organization adopts complex processes such as projects and programs to perform its business, and uses project, program and project portfolio management as specific business processes. Turner \& Keegan (loc cit) of course suggest that the project-based organizations adopts project-based ways of working perforce, required by the fact that it delivers tailored or bespoke products or services to its customers. The case companies described above recognized early on that the work they were doing for customers required them to adopt project-based ways of working (Söderlund and Tell, 2009; Bergman et al., 2013; Kwak et al., 2015). Maylor et al. (2015) define that project-based organization as one which uses projects and project management as it primary business processes, though their focus is primarily on strategic intent and configuration or fit. Artto and Kujala (2008) also focus on the adoption of projects and project management as the business processes adopted. Indeed, the Finnish school has written many papers on the adoption of project management as a business model, and how that influences other processes and practices within the organization; (see for instance Turkulainen et al., 2013, where they discuss the project-sales interface; and Artto et al., 2015, where they discuss the projects-services interface). Because the business processes adopted by the project-based organization use projects, programs and portfolios, we suggest the embedding of projects, (Bergman et al., 2013), is appropriate for the design of the project-based organizations, Fig. 2.

\subsection{Project culture}

Gareis \& Huemann (loc cit) suggest the project-oriented organization adopts a project management culture, which makes it better able to deal with uncertainty, contradiction, change and collaboration. Functional managers may be reluctant to adopt a project culture, (Turner \& Keegan, loc cit). In the classically managed organization, the functional hierarchy is the governance structure for internal transactions; in the project-based organization, the project should be the governance structure for both internal and external transactions, 
but functional managers can be reluctant to release control to project managers. Keegan et al. (2012) investigate how responsibility for human resource management can be shared between line managers, functional managers and human resource managers. They found annual appraisals are usually conducted in the line, because it is necessary to take a perspective longer than individual projects. They assumed line managers, when conducting annual appraisals, would seek information from the managers of projects their staff had been working on about the performance of their staff. However, one line manager they interviewed said he did not seek information from the project managers because it reduced his authority. Turner (2014) also reports a case of a company he was helping to convert from a line focus to a project focus. They were trying to change from aligning the governance structure with the functional hierarchy to the project. But in the organization, managers were rewarded according to the number of subordinates they had, (not their impact on the bottom line). Line managers, with many subordinates, were senior people. Project managers, with no direct subordinates, were so junior they did not have procurement authority to buy coffee for a meeting with the client. These are examples of how the culture of the company can work against the adoption of a project-oriented culture. The company that makes the strategic decision to be project oriented must work to adopt a project-oriented culture, by addressing the balance between project and functional managers, and properly rewarding project managers for their contribution to the bottom line. Both line managers and project managers must adopt appropriate behaviours.

We said in Section 1 that Turner \& Keegan (loc cit) said that the functional hierarchy can give the organization cohesion and culture. Projects, which are temporary organizations cannot provide the organization with cohesion and culture. Being temporary, they damage cohesion and cannot define the culture of the organization. Cohesion and culture must be provided by the functional organization, but it needs to recognize that project and program management are the primary business processes adopted, and adopt an appropriate culture. The ability of the functional organization to do that has been described as projectivity (Turner, 2014).

\subsection{Fit}

Galbraith (2014), in the development of his Star Model, says that there should be an alignment between the five elements of the model. We propose that there should be an alignment between the five elements of the second star. Having made the strategic decision to be project oriented:

- the organization adopts project-based working as its primary business processes, (Gareis \& Huemann, loc cit; Turner \& Keegan, loc cit; Maylor et al., 2015)

- it adopts a project culture, where it is recognized that projects are the primary governance structure for internal and external transactions, and people adopt appropriate behaviours, (Turner \& Keegan, loc cit; Gareis \& Huemann, loc cit)
- it designs organizational structures to provide fit between processes and strategy; between line and projects; between processes in different functions; between the internal and external contexts, (Huemann et al., 2007; Keegan et al., 2012)

- it adopts human resource management practices to reflect the churn that project-based working implies, (Keegan et al., 2012).

Maylor et al. (2015) identify that configuration and fit are two of the four components of operational strategy in manufacturing organizations, and so propose them as significant elements in the design of the project-based organization. Based on their research, they identified that configuration comprised capability, capacity, process, support governance and outsourcing. ${ }^{4}$ We give process its own position in our model, and governance we place under strategy, but the remainder are components of structure. With fit Maylor et al. (2015) focused on external fit, and the alignment of strategy with the products and services the organizations deliver to external customers. That would apply to both Type 1 and Type 2 organizations as defined by Turner \& Keegan (loc cit), because although Type 2 organizations are supplying products or services to parts of the same parent organization, it is still outside the organizational unit under consideration. Thus the work of Maylor et al. (2015) also applies to the project-based parts of project-led or projectsupported organizations (Hobday, 1998, 2000). Thomas and Mullaly $(2008,2009)$ in their research into the value of project management also identified fit as an issue, but they focused more on internal fit, compatibility between the business processes within the organization.

Söderlund and Tell (2009) and Kwak et al. (2015) describe how the case companies developed appropriate competencies for the management of projects, and adapted the organization structure to fit project-based working as it adopted project working through the different stages. Bergman et al. (2013) focus on standardization of project work, and on how the company's structure, processes and employment-base changed in line with the company's increasing volume of projects.

\subsection{Churn}

Huemann et al. (2007) in developing their model for Human Resource Management in the project-based organization say there is considerable churn in the organization (see Fig. 4). Every time a project starts or finishes the human resource configuration of the organization changes. People need to be assigned to projects and reassigned at the end of projects. Keegan et al. (2012) identified that HRM practices need to be applied both on the project and in the line, and line managers, project managers and human resource managers share

\footnotetext{
${ }^{4}$ Configuration as defined by Maylor et al. (2015), differs from the term as used by Van de Ven et al. (2013) following Meyer et al. (1993). The former use it to mean the structures adopted for project-based working, whereas the latter use it to mean the distinct comprehensive systems of multiple interrelated design choices.
} 

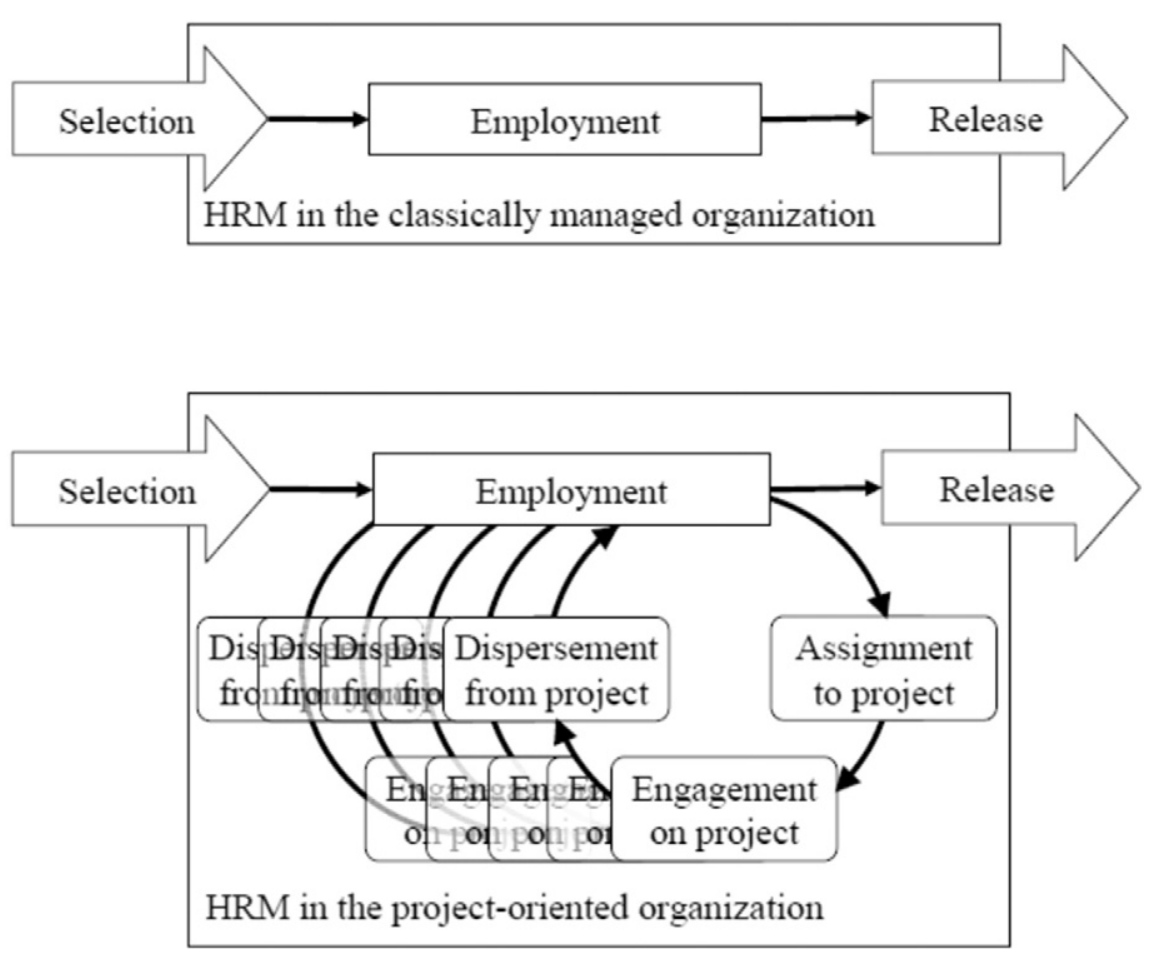

Fig. 4. HRM in the classically managed organization vs HRM in the project-based organization to illustrate churn in the latter (after Huemann et al., 2007).

responsibility for the management of people on projects. The churn is one of the factors creating higher stress for employees identified by Turner et al. (2008). Earlier, we identified this churn, and the sharing of responsibility between the permanent line and temporary projects and programs as a primary reason why a novel form of organization is required (Puranam et al., 2014). According to their model, projects, programs and portfolios within the organization are agents, as are the people working on them. Every time a project or program starts or finishes, the agents within the organization change, as does the configuration of agents within organizational sub-units. Gareis \& Huemann (loc cit) suggest that people working in this environment need to be better able to deal with uncertainty, contradiction, change and collaboration. Söderlund and Tell (2009) primarily focus on how Asea/ABB developed the appropriate competencies through the four epochs they identify. Keegan et al. (2012) also identified that the Human Resource Management Department is often based in a functional part of the organizations and so imposes on the organizations HRM practices appropriate for functional-based working and not project-based working.

\subsection{Summary}

We have identified the five nodes in the upper star of Fig. 3 as factors that influence the design of the project-based organiza-tion. Accordingly we suggest the following propositions:

Proposition 2.1. The project-based organizations need to make the strategic decision to be project-oriented, and adopt projects, programs and project portfolios to perform its work.
Proposition 2.2. The project-based organization will use project management, program management and project portfolio management as its main business processes.

Proposition 2.3. The project-based organization needs to adopt a project-oriented culture, where everybody working in the organization recognizes that is the organization's way of doing business and adopts appropriate behaviours. Reward structures within the organizations should reflect the nature of project-based working.

Proposition 2.4. The project-based organizations should develop organizational structures to create a fit between the processes adopted and organization strategy; between the processes adopted in the line and on projects, between the processes adopted in different functions, and the processes adopted and the external context. In particular, the processes adopted in parts of the organization that are still functional, such as the Human Resource Management and Finance Departments should reflect project-based working.

Proposition 2.5. Project-based working creates churn within the organization, where agents are constantly created and disbanded, and the assignment of human resources to those agents is constantly changing. Thus there is a constant remapping of tasks to agents, information to agents and rewards to agents. An organizational approach needs to be adopted which recognizes this constant remapping, while maintaining cohesion within the organization.

Proposition 2.6. These five factors influence each other, and the five elements of Galbraith's (2014) Star Model. There needs to be an alignment between the ten elements of the two stars. 


\section{Conclusion}

Our two research questions are:

RQ1: What design choices are available for the design of the project-based organization?

RQ2: What factors influence the selection of design choices?

In answer to the first question we propose a modified version of Galbraith's (2014) Star Model, Fig. 1, as defining the elements that need to be included in the design of the project-based organization. We suggest the design will adopt a contingency approach, view various organizational arrangements as complementarities and conceptualize projects as temporary organizations nested in the parent organization. These design choices should be aligned with those of the project-based organization (Bergman et al., 2013; Van de Ven et al., 2013; Whittington et al., 1999; Zenger and Hesterly, 1997).

The project management literature has covered all the elements of the Star Model to a greater or lesser extent. However, no papers discussed the holistic design of the project-based organization. Thus, this paper uncovers the current focus of the project management literature on 'isolated' organizational design choices. As noted above, presenting the results of the full bibliometric study is out of the scope. However, such study is being conducted, (Miterev et al., submitted for publication). Its results will augment the preliminary results presented here and will evaluate project-based management literature from the organizational design perspective.

In answer to the second question we propose a second star model, Fig. 3. In designing the project-based organization, the five elements that need to be taken account of are: project-orientation; project working; project culture; churn; and fit or configuration.

This paper opens up the discussion on the project-based organization from an organization design perspective. This is in accordance with the recent calls by scholars to build upon strategic management (Drouin and Jugdev, 2013) and organization theory (Söderlund et al., 2014; Söderlund, 2013) to advance the organizational project management literature. Project management research benefits from theoretical pluralism (Söderlund, 2011; Turner et al., 2010), and the organization design perspective could become a valuable contribution to the discourse. The paper represents only a modest first step in this direction by applying a new perspective, but it offers several important implications for research.

First, the organization design research stream can provide a fresh yet almost unexplored potential to enhance the studies on organizational aspects of the project-based organization. The organization design literature itself has been evolving over several decades and now embodies diverse theoretical perspectives (Baum and Rowley, 2002; Van de Ven et al., 2013). While our paper focused on applying and tailoring one of the classical models in the project-based context to show its potential and open the discussion on the topic, future research could also build upon more nuanced studies within the stream.
Besides the definitive models, the field can offer wellelaborated concepts, for example fit and adaptation, methodological approaches, and overall perspectives: contingency, configuration, complementarities, complexity and creativity (Van de Ven et al., 2013).

Second, the paper draws attention to the importance of adopting an holistic approach and studying interdependencies between design choices in the project-based organization. The notion of significant interdependence between organizational arrangements and the danger of either internal misfits or piecemeal organizational changes is well recognized in literature on organization design (for example Meyer et al., 1993; Whittington et al., 1999). However, as it was shown in the paper, this is in sharp contrast with common practice in the project management literature, where separate organizational arrangements or properties are often studied independently of each other. Fully acknowledging the importance of such studies for the deeper understanding of the nature of the organizational mechanisms, we argue that studies taking holistic stance on the design of project-based organization can enrich the field.

Third, the paper addresses temporality and transient nature of projects in the design of the project-based organization and thus contributes back to the field of organization design. There have been some calls from the research community to pay closer attention to the transient nature of projects as an important contingency for project-based organizing (Söderlund and Tell, 2011). Puranam et al. (2014) suggest that an organization is a mapping of goals to tasks, tasks to agents, information to agents and rewards to agents. Because projects and programs are temporary agents, their definition is constantly changing in the project based organization. A solution needs to be found which provides the cohesion of a single organization design which addresses the constant remapping. Turner \& Keegan (loc cit) identified that the cohesion was lost in many of the organizations that adopted purely project-based ways of working on the late 1980s and early 1990s.

These considerations prompt several new research directions. One is the empirical validation and adjustment of the conceptual model. Another promising topic is studying interrelationships between various dimensions and possible synergetic effects under complementarities perspective (Whittington et al., 1999) to enhance our understanding of the concept of internal fit in the context of project-based organization. Besides, there is an opportunity to take stock of existing theoretical concepts within the organization design field, such as fit, alignment and misalignment, adaptation etc., and to apply them to the project-based context. Finally, project-based organizations do not comprise a homogeneous category (for instance see Hobday, 2000; Larson and Gobeli, 1989; Turner \& Keegan, loc cit; Whitley, 2006). In line with the contingency perspective, future research should address the design choices and contextual characteristics specific to the various types of project-based organizations. Moreover, the performance implications of various organization design choices should be explored both theoretically and empirically.

The authors believe that these suggestions are not and (cannot be) exhaustive for such a broad emerging research stream as the design of the project-based organization. We 
invite contributions from both project management and organization theory and design scholars to explore this intricate topic. Considering the potential importance of the academic and managerial implications of such studies, the efforts appear well justified.

\section{Conflict of interest statement}

The authors declare that the manuscript has not been submitted or published elsewhere. There are no other potential conflicts of interest in regards to this submission.

\section{Acknowledgements}

This paper is produced as part of the EMJD Programme European Doctorate in Industrial Management (EDIM) funded by the European Commission, Erasmus Mundus Action 1.

\section{References}

Archibald, R.D., 1992. Managing High-technology Programs and Projects. second ed. Wiley, New York.

Artto, K., Kujala, J., 2008. Project business as a research field. Int. J. Manag. Proj. Bus. 1 (4), 469-497.

Artto, K., Valtakoski, A., Kärki, H., 2015. Organizing for solutions: how project-based firms integrate project and services businesses. Ind. Mark. Manag. 45, 70-83.

Arvidsson, N., 2009. Exploring tensions in projectified matrix organisations. Scand. J. Manag. 25 (1), 97-107.

Baum, J.A., Rowley, T.J., 2002. Companion to organizations: an introduction. In: Baum, J.A. (Ed.), Companion to Organizations. Blackwell Publications, pp. 1-34 (Chapter 1).

Bergman, I., Gunnarson, S., Räisänen, C., 2013. Decoupling and standardization in the projectificaton of a company. Int. J. Manag. Proj. Bus. 6 (1), $106-128$.

Bernasco, W., de Weerd-Nederhof, P.C., Tillema, H., Boer, H., 1999. Balanced matrix structure and new product development process at Texas Instruments materials and controls division. R\&D Manag. 29 (2), 121-131.

Burns, T., Stalker, G., 1961. The Management of Innovation. Tavistock, London.

Canonico, P., Söderlund, J., 2010. Getting control of multi-project organizations: combining contingent control mechanisms. Int. J. Proj. Manag. 28 (8), 796-806.

Cattani, G., Ferriani, S., Frederiksen, L., Täube, F. (Eds.), 2011. Advances in strategic managementProject-Based Organizing and Strategic Management vol. 28. Emerald Insight, Bradford, GBR.

Chandler, A.D., 2013. Strategy and Structure: Chapters in the History of the Industrial Enterprise. Martino Fine Books, Eastford, CT.

DeFillippi, R.J., Arthur, M.B., 1998. Paradox in project-based enterprise: the case of film making. Calif. Manag. Rev. 40 (2), 124-139.

Donaldson, L., 2001. The Contingency Theory of Organizations. Sage, Thousand Oaks, CA.

Doty, D.H., Glick, W.H., Huber, G.P., 1993. Fit, equifinality, and organizational effectiveness: a test of two configurational theories. Acad. Manag. J. 36 (6), 1196-1250.

Drouin, N., Jugdev, K., 2013. Standing on the shoulders of strategic management giants to advance organizational project management. Int. J. Manag. Proj. Bus. 7 (1), 61-77.

Dunn, S.C., 2001. Motivation by project and functional managers in matrix organizations. Eng. Manag. J. 13 (2), 3-10.

Ennen, E., Richter, A., 2010. The whole is more than the sum of its parts - or is it? A review of the empirical literature on complementarities in organizations. J. Manag. 36 (1), 207-233.
Galbraith, J.R., 1971. Matrix organization designs: how to combine functional and project forms? Bus. Horiz. 14 (1), 29-40.

Galbraith, J.R., 1973. Designing Complex Organizations. Addison-Wesley Longman Publishing.

Galbraith, J.R., 2008. Designing Matrix Organizations that Actually Work: How IBM, Procter \& Gamble and Others Design for Success. Jossey-Bass.

Galbraith, J.R., 2014. Designing Organizations: Strategy, Process and Structure at the Business Unit and Enterprise Level. third ed. Jossey-Bass, San Francisco.

Gareis, R., 1990. Management by projects: the new management strategy of the project-oriented company. In: Gareis, R. (Ed.), Handbook of Management by Projects. Manz, Vienna, pp. 35-47.

Gareis, R., 2005. Happy Projects! Manz, Vienna.

Gareis, R., Huemann, M., 2007. Maturity models for the project-oriented company. In: Turner, J.R. (Ed.), The Gower Handbook of Project

Management, fourth ed. Gower, Aldershot, pp. 183-208.

Geraldi, J., 2008. The balance between order and chaos in multi-project firms: a conceptual model. Int. J. Proj. Manag. 26 (4), 348-356.

Geraldi, J., 2009. Reconciling order and chaos in multi-project firms. Int J. Manag. Proj. Bus. 2 (1), 149-158.

Gulati, R., Puranam, P., Tushman, M., 2012. Meta-organization design: rethinking design in interorganizational and community contexts. Strateg.

Manag. J. 33 (6), 571-586.

Hackman, J.R., Oldham, G.R., 1975. Development of the job diagnostic survey. J. Appl. Psychol. 60 (2), 159-170.

Hanisch, B., Wald, A., 2011. A project management research framework integrating multiple theoretical perspectives and influencing factors. Proj.

Manag. J. 42 (3), 2-22

Hedlund, G., 1994. A model of knowledge management and the $\mathrm{N}$-form corporation. Strateg. Manag. J. 15 (S2), 73-90.

Hobday, M., 1998. Product complexity, innovation and industrial organization. Res. Policy 26 (6), 689-710.

Hobday, M., 2000. The project-based organization: an ideal form for managing complex products and systems? Res. Policy 29 (7), 871-893.

Huemann, M., 2014. Managing the project-oriented organization. In: Turner, J.R. (Ed.), The Gower Handbook of Project Management, fifth ed. Gower, Aldershot, pp. 463-476.

Huemann, M., 2015. Human Resource Management in the Project-oriented Organization: Towards a Viable System for Project Personnel. Gower, Aldershot.

Huemann, M., Keegan, A.E., Turner, J.R., 2007. Human resource management in the project oriented company: a critical review. Int. J. Proj. Manag. 25 (3), 312-320.

Jerbrant, A., 2013. Organising project-based companies: management, control and execution of project-based industrial operations. Int. J. Manag. Proj.

Bus. 6 (2), 365-378

Keegan, A.E., Turner, J.R., 2000. Managing human resources in the project-

basertganization. In: Turner, J.R., Simister, S.J. (Eds.), The Gower Handbook of Project Management, third ed. Gower, Aldeshot, pp. 693-708.

Keegan, A.E., Turner, J.R., 2001. Quantity versus quality in project based learning practices. Manag. Learn. 32 (1), 77-98 (special issue on

Project-based Learning).

Keegan, A.E., Turner, J.R., 2002. The management of innovation in project based firms. Long Range Plan. 35 (4), 367-388.

Keegan, A.E., Huemann, M., Turner, J.R., 2012. Beyond the line: exploring the HR responsibilities of line managers, project managers and the HR department in four project-oriented companies. Int. J. Hum. Resour. Manag. 23 (15), 3085-3104.

Knight, K., 1976. Matrix organization: a review. J. Manag. Stud. 13 (2), 111130. Kuprenas, J.A., 2003. Implementation and performance of a matrix organization structure. Int. J. Proj. Manag. 21 (1), 51-62 Kwak, Y.H., Sadatsafavi, H., Walewski, J., Williams, N.L., 2015. Evolution of project based organization: a case study. Int. J. Proj. Manag. 33 (8), 1652-1664. Larson, E.W., Gobeli, D.H., 1989. Significance of project management structure on development success. IEEE Trans. Eng. Manag. 36 (2), 119-125 Lawrence, P.R., Lorsch, J.W., 1967. Organization and Environment: Managing Differentiation and Integration. Harvard Business Press, Boston, MA.

Lengnick-Hall, C.A., Lengnick-Hall, M.I., 1988. Strategic human resources management: a review of the literature and a proposed typology. Acad. Manag. Rev. 13 (3), 454-470. 
Lindkvist, L., 2004. Governing project-based firms: promoting market like processes within hierarchies. J. Manag. Gov. 8 (1), 3-25.

Lundin, R.A., Söderholm, A., 1995. A theory of the temporary organization. Scand. J. Manag. 11, 437-455.

Lundin, R.A., Arvidsson, N., Brady, T., Ekstedt, E., Midler, C., Sydow,

J., 2015. Managing and Working in Project Society: Institutional Challenges of Temporary Organizations. Cambridge University Press, Cambridge.

Luo, B.N., Donaldson, L., 2013. Misfits in organization design: information processing as a compensatory mechanism. J. Organ. Des. 2 (1), 2-10.

March, J.G., Simon, H.A., 1958. Organizations. Wiley, New York. Martinsuo,

M., 2013. Project portfolio management in practice and in context.

Int. J. Proj. Manag. 31 (6), 794-803.

Maylor, H., Turner, N., Murray-Webster, R., 2015. It worked for manufacturing ...! Operations strategy in project-based organizations. Int. J. Proj. Manag. 33 (1),

$103-115$.

Meyer, A.D., Tsui, A.S., Hinings, C.R., 1993. Configurational approaches to organizational analysis. Acad. Manag. J. 36 (6), 1175-1195.

Milgrom, P., Roberts, J., 1995. Complementarities and fit strategy, structure, and organizational change in manufacturing. J. Account. Econ. 19 (2),

179-208.

Mintzberg, H., 1979. The Structuring of Organizations. Prentice-Hall, Englewood Cliffs, NJ.

Miterev, M., Engwall, M., Jerbrant, A., 2016. Exploring program management competences for various program types. Int. J. Proj. Manag. 34 (3),

545-557.

Miterev, M., Turner, J.R., Mancini, M., 2016. The Organization Design Perspective on the Project-based Organization: A Structured Review (submitted for publication).

Müller, R., 2009. Project Governance. Gower, Aldershot.

Nadler, D.A., Tushman, M.L., 1999. The organization of the future: strategic imperatives and core competencies for the 21 st century. Organ. Dyn. 28 (1),

$45-60$

Packendorff, J., 1995. Inquiring into the temporary organization: new directions for project management research. Scand. J. Manag. 11 (4), 319-333. Perrow, C., 1986. Complex Organizations: A Critical Essay. third ed. McGrawHill, New York, NY.

Prencipe, A., Tell, F., 2001. Inter-project learning: processes and outcomes of knowledge codification in project-based firms. Res. Policy 30 (9),

1373-1394.

Puranam, P., Alexy, O., Reitzig, M., 2014. What's "new" about new forms of organizing. Acad. Manag. Rev. 39 (2), 162-181.

Siggelkow, N., Levinthal, D.A., 2003. Temporarily divide to conquer: centralized, decentralized, and reintegrated organizational approaches to

exploration and adaptation. Organ. Sci. 14 (6), 650-669.

Simons, R., 1995. Levers of Control: How Managers Use Innovative Control Systems to Drive Strategic Renewal. Harvard Business School Press, Boston, Mass.

Skinner, W., 1969. Manufacturing: the missing link in corporate strategy. Harv. Bus. Rev. 47 (3), 136-146.

Skinner, W., 1974. The focused factory. Harv. Bus. Rev. 52 (3), 113-119.

Söderlund, J., 2011. Pluralism in project management: navigating the crossroads of specialization and fragmentation. Int. J. Manag. Rev. 13 (2),

153-176.

Söderlund, J., 2013. Pluralistic and processual understanding of projects and project organizing; towards theories of project temporality. In: Drouin, N., Müller, R., Sankaran, S. (Eds.), Novel Approaches to Organizational Project Management Research. Translational and Transformational. Copenhagen Business School Press, Copenhagen, pp. 117-136.

Söderlund, J., Bredin, K., 2006. HRM in project-intensive firms: changes and challenges. Hum. Resour. Manag. 45 (2), 249-265.

Söderlund, J., Tell, F., 2009. The P-form organization and the dynamics of project competence: project epochs in Asea/ABB, 1950-2000. Int. J. Proj.

Manag. 27 (2), 101-112.

Söderlund, J., Tell, F., 2011. The P-form corporation - contingencies, characteristics, and challenges. In: Morris, P.W.G., Pinto, J.K., Söderlund, J. (Eds.), The Oxford Handbook of Project Management. Oxford University Press, New York, pp. 201-223
Söderlund, J., Hobbs, B., Ahola, T., 2014. Project-based and temporary organizing: reconnecting and rediscovering. Int. J. Proj. Manag. 32 (7), 1085-1090.

Sydow, J., Lindkvist, L., DeFillippi, R., 2004. Project-based organizations, embeddedness and repositories of knowledge: editorial. Organ. Stud. 25 (9), 1475-1489.

Thomas, J., Mullaly, M., 2008. Researching the Value of Project Management. Project Management Institute, Newtown Square, PA.

Thomas, J., Mullaly, M., 2009. Exploring the dynamics of value and fit: insights from project management. Proj. Manag. J. 40 (1), 125-135.

Thompson, J.D., 1967. Organizations in Action. McGraw Hill, New York.

Turkulainen, V., Kujala, J., Artto, K., Levitt, R.E., 2013. Organizing in the context of the global project-based firm - the case of sales-operations interface. Ind. Mark. Manag. 42 (2), 223-233.

Turner, J.R., 2014. The Handbook of Project-based Management. fourth ed. McGraw-Hill, New York.

Turner, J.R., Keegan, A.E., 1999. The versatile project-based organisation: governance and operational control. Eur. Manag. J. 17 (3), 296-309.

Turner, J.R., Keegan, A.E., 2000. The management of operations in the projectbased organization. J. Chang. Manag. 1 (2), 131-148.

Turner, J.R., Keegan, A.E., 2001. Mechanisms of governance in the projectbased organization: the role of the broker and steward. Eur. Manag. J. 19

(3), 254-267.

Turner, J.R., Müller, R., 2003. On the nature of the project as a temporary organization. Int. J. Proj. Manag. 21 (1), 1-8.

Turner, J.R., Keegan, A.E., Crawford, L.H., 2002. Delivering improved project management maturity through experiential learning. Proj. Manag. 8 (1), 72-81.

Turner, J.R., Huemann, M., Keegan, A.E., 2008. Human resource management in the project oriented company: employee well-being and ethical treatment. In: Brady, T., Söderlund, J. (Eds.), International Journal of Project Management, Special Issue: IRNOP X, Innovation in Projects 26(5), pp. $577-585$.

Turner, J.R., Huemann, M., Anbari, F.T., Bredillet, C.N., 2010. Perspectives on Projects. Routledge, New York.

Turner, J.R., Pinto, J.F., Bredillet, C.B., 2011. The evolution of project management research: the evidence from the journals. In: Morris, P.W.G., Pinto, J.F., Söderlund, J. (Eds.), The Oxford Handbook of Project Management. Oxford University Press, Oxford.

Turner, J.R., Ledwith, A., Kelly, J.F., 2012. Project management in small to medium-sized enterprises: tailoring the practices to the size of company. Manag. Decis. 50 (5), 942-957 Special Issue for the 50th Anniversary.

Van de Ven, A.H., Ganco, M., Hinings, C.R., 2013. Returning to the frontier of contingency theory of organizational and institutional design. Acad. Manag. Ann. 7 (1), 393-440

Waterman, R.H., Peters, T., 2015. In Search of Excellence: Lessons From America's Best-run Companies (Profile Business Classics). Profile Books, London.

Whitley, R., 2006. Project-based firms: new organizational form or variation on a theme. Ind. Corp. Chang. 15 (1), 77-99.

Whittington, R., Pettigrew, A., Peck, S., Fenton, E., Conyon, M., 1999. Change and complementarities in the new competitive landscape: a European panel study, 1992-1996. Organ. Sci. 10 (5), 583-600 (Focused Issue: Coevolution of Strategy and New Organizational Forms).

Williamson, O.E., 1976. Markets and Hierarchies: Analysis and Antitrust Implications. The Free Press, Boston.

Williamson, O.E., 1996. The Mechanisms of Governance. Oxford University Press, New York

Winch, G.M., 2004. Rethinking project management: project organizations as information processing systems. Innovations: Project Management Research. Project Management Institute, Newtown Square, PA.

Woodward, J., 1965. Industrial Organization: Theory and Practice. Oxford University Press, New York, NY.

Wright, P., McMahan, G., 1992. Theoretical perspectives for strategic human resource management. J. Manag. 18 (2), 295-320.

Zenger, T.R., Hesterly, W.S., 1997. The disaggregation of corporations: selective intervention, high-powered incentives, and molecular units. Organ. Sci. 8 (3), 209-222. 